\title{
Sustainable Development Goals: Reaching People through Their Mother Tongue
}

\author{
Jefwa Mweri \\ Department of Kiswahili and Kenya Sign Language Research Project (KSLRP), University of Nairobi, Kenya
}

Received November 4, 2019; Revised December 6, 2019; Accepted December 17, 2019

Copyright $@ 2020$ by authors, all rights reserved. Authors agree that this article remains permanently open access under the terms of the Creative Commons Attribution License 4.0 International License

\begin{abstract}
People's languages are vitally important to them. Through language, people communicate, share meaning and experience their sense of individual and community identity. Recognizing the profound importance that people place on their languages is a core insight for tackling poverty and hunger. UNESCO: The Sustainable Development Goals (SDGs) are essentially an expansion of the Millennium Development Goals (MDGs). The SDGs were a reaction to the weakness of the MDGs. Where the MDGs were only eight, the SDGs are seventeen. The SDGs are a new and universal set of goals, targets and indicators that UN member states will be expected to use to frame their agendas and political policies over the next 15 years. The question that comes to mind when we think of the implementation and success of these SDGs is how UN member states will be able to reach the grassroots with these goals for them to be translated into reality. Mother tongue (MT) or local languages definitely have an important role to play. This paper therefore examines the role of MT or local languages in the achievement of these goals. It examines the power of language as a tool of development. Whether it is about ending hunger, promoting health, equitable quality education etc., it is important to note that language-based development is essential for meeting these goals. For each of the goals set, local languages or Mother tongue has an important role to play. These goals envisage a participatory approach to economic development and genuine participation in the development process that is dependent on two-way communication between the implementers of the SDGs and the people, this requires engaging people in the language they speak and understand i.e. the MT or local languages. MT is the language through which people have learnt how to think and how to communicate and therefore it can be harnessed to ensure that communities develop local solutions to the SDGs challenges. This paper argues that just like there is a human rights based approach to economic development, it is equally important to recognize the role of language in general and mother tongue or local
\end{abstract}

languages in particular in the drive towards sustainable development goals. We argue for a language-based approach towards the SDGs in ensuring their success. In this paper we shall examine each SDG and critically analyze the role of mother tongue in their achievement.

Keywords Sustainable Development Goals, Local Languages, Mother Tongue, Development

\section{Introduction}

Every year, in Kenya, the University of Nairobi graduates over ten thousand students in different fields of study. The University of Nairobi is one of the 50 plus universities in Kenya which produce an estimated 25,00030,000 graduates annually. After graduation these eager graduates are normally rearing to go and use their knowledge for the development of the country. It is graduates like these that may hold the key to the success of the SDGs. However, a student of agriculture for example who graduates from the University of Nairobi and is posted to a rural area away from his own rural set up, so as to use his knowledge to enhance agricultural productivity and thus alleviate poverty (SDGs 1 and 2) might be in for a rude shock to realize that all he/she learnt cannot translate into any meaningful practice due to a language barrier. How then do they and many others like them in different fields of development contribute to sustainable development?

On 25 September 2015, world leaders at the United Nations Sustainable Development Summit adopted the 2030 Agenda for Sustainable Development, which includes a set of 17 Sustainable Development Goals (SDGs) to end poverty, fight inequality and injustice, and tackle climate change etc. by 2030 [1]. How then do nations meet this international desire for sustainable development or "Development that meets the needs of the present without compromising the ability of future generations to meet 
their own needs? [2] This type of development must take into consideration the most important aspect of its implementation - that is Language.

The achievement of these goals is mostly dependent on all stakeholders including: governments, the private sector, civil society, to play their part effectively. More importantly, however, is the fact that these stakeholders may not achieve much if they keep ignoring the important role of communication through MT or local languages in ensuring that these goals are achieved. Bonvillian [3] asserts that, the primary means of interaction between people is language. Speakers use language to convey thoughts, feelings, intentions and desires to others. The language links interlocutors in a dynamic, reflexive process. Each language is a way of seeing and reflecting the delicate nuances of cultural perceptions. Thus the University of Nairobi student above could not convey his knowledge to the local population, most likely, because the language he/she studied his/her agriculture in (in his case English) did not resonate with or reflect the delicate nuances of cultural perceptions of the rural community he was posted to.

The questions we seek to answer in this paper include:

1. How does diversity in language use affect the passage on of messages from one person to another, given that language is a culture-based system of symbols that people use for purposes of encoding and decoding information?

2. How do the SDGs that are framed in a language that is foreign to a huge population of the world, reach the grassroots so that they can be translated into a plan of action?

The SDGs are meant to ensure that the whole process of economic development is a participatory one.

However, genuine participation can only occur if a two way communication process exists. This process entails that the governments and other players engaging people in the language they speak and understand i.e. the MT or local languages on issues of sustainable development.

The SDGs (listed below) are a new, universal set of goals, targets and indicators that UN member states are expected to use to frame their agendas and political policies over the next 15 years. [4]

1. No poverty

2. Zero hunger

3. Good health and wellbeing.

4. Quality education.

5. Gender equality.

6. Clean water and sanitation.

7. Affordable and clean energy

8. Decent work and economic growth.

9. Industry, innovation and infrastructure.

10. Reduced inequalities.

11. Sustainable cities and communities.

12. Responsible production and consumption.

13. Climate action.
14. Life below water.

15. Life on land.

16. Peace, justice and strong institution.

17. Partnership for the goal.

This paper does not set out to examine the merits and demerits of the SDGs but rather it examines the place of MT or local languages in the achievement of these goals. (In this paper, the terms mother tongue and local languages are used interchangeably). The paper examines the power of language especially mother tongue as a tool of development. In most instances, the MT is the language through which people have learnt how to think and how to communicate and therefore it can be harnessed to ensure that communities develop local solutions to the SDGs challenges. We argue, in this paper for a language based approach towards the SDGs to ensure their success. In the subsequent sections below we shall examine each SDG and analyze the role of mother tongue in their achievement. However, we begin with an examination of the issue of language and development.

\section{Language and Development}

Over the years, the so called 'dominant languages' have been used in development discourse at the expense of the use of the so called 'minority languages.' The dominance of these languages is not based on superiority but rather on some perceived power and influence over the so called "minority languages." This power and influence is manifested in the use of these so called "dominant languages" in official communication. Though they may not be the most used languages, they still have a lot influence wherever they are used. This influence is product of factors such as colonialism which placed these languages above the local used language in countries which were colonised. For instance, according to Wikipedia, English has a total population of 379 million speakers, French with a total 77.2 million speakers and Portuguese with a total of 220 million speakers worldwide. These three language are thus considered dominant in the African continent if examined side by side local languages for historical reasons. Kenya, with a population of over 47 million, is estimated to have about 7-10 million Kenyans speak English. This is about 16\% of the population as compared to Kiswahili which is estimated to be spoken by $70 \%$ of the population. Despite these statistics English in Kenya is considered a dominant language used as a medium of instruction in schools, as the language of business and finance, used on the internet, used in most government documents and communication etc. These 'dominant languages' are also used in education (as medium of instruction in schools) and in almost all facets of life in most developing countries often with disastrous results as noted by UNESCOs advocacy for local languages. [5] 
These "dominant languages" are also used in national economies (courtesy of the elites who chose to retain them even after independence to their advantage) in programmes that seek to eradicate poverty with seemingly disastrous results too since the poor find it hard to adjust to these languages at the expense of their own local languages. This paper examines the link between the use of MT and economic development in light of the SDGs. Programmes committed to human development just like the SDGs may definitely require some form of literacy but this literacy need not be in a foreign language as the example of the agriculture graduate above shows. The graduate immediately finds out that despite having the agricultural knowledge and skills learnt at the University of Nairobi, this knowledge and skills were however learnt in a foreign dominant language in this case English. This renders his literacy skills useless since they do not assist him to do his job since most of the residents at his work place can only speak their MT.

Compare the above discussed case of the University of Nairobi student to a scenario where a local village elder who has gone through Mother tongue literacy programme, becomes literate in his mother tongue and can read and write development literature in the same. This elder, who is obviously less educated as compared to our graduate, will be able to impart knowledge on issues of development better because he is able to reach his people in a language they understand.

The over reliance of foreign languages such as English, French and Portuguese, that happens in most developing countries, is based on the false belief that English (read foreign) language education for example equals development (since most dominant languages are also foreign). This false belief has seen English being promoted and used as an important factor in international development programmes. In works exploring the relationship between development and language education, development is defined as the process of reducing poverty while also expanding people's choices, with its ultimate aim being to increase participants' control over their own development [6], [7].The proponents of this definition go further to emphasize the role that language education can play in helping people gain the resources to lift themselves out of poverty and increase their ability to participate in world economic systems from which they have previously been excluded. They, however, link this role of language education to English by saying: "Given the current status of English as the pre-eminent global language, much of this stress on language education becomes, in fact, a stress on English language education.” [8]

According to Erling and Seargeant, [9] the notion of English as a language of international development is based on four main assumptions:

1. English as a global language

2. English and economic value

3. English as a language for education

\section{English as a language of technology}

Because English is globally used for purposes of reaching multitudes, then it is assumed that it is the most viable option to be used to present issues of international development. There is also the presumption, which Bourdieu [10] calls "linguistic capital" based on the belief that the possession of certain linguistic resources can lead to improved social opportunities - which possession of English in some instances can lead to economic advancement. This is an approach that Okombo [11] calls the "market -value" argument which as he asserts boils down to the question of what one gets in their world of opportunities by being able to speak or write using a particular language.(P.8). For a long time this has been the approach most Africans have taken be it in Anglophone Africa where English is used or Francophone Africa where French is used or where Portuguese is also used. Apart from the mistaken belief that the possession of English leads to economic advancement, it has also been promoted as a key factor for economic competitiveness and educational advancement. English is also often framed within the development discourse as a means of allowing access to technology, which in turn is seen as facilitating learning and supporting educational change. [12]

Imam [13] argues that it is 'unethical' to allow education to sustain the illusion of English as a tool of economic and social advancement. She also notes, 'by no means everyone who acquires English will join the local or global elite', and for these reasons a simplistic formula which equates English competence with economic mobility can be perniciously misleading in terms of the false assumptions it promotes. This basically means that there is a belief that in developmental contexts, there will be a direct correlation between the acquisition of English and economic advancement. Contrary to this belief, other studies suggest the importance of MT-based instruction for educational quality. Benson [14], Trudell [15] and Hanushek \& Woessmann [16], show a correlation between educational quality and economic development.

However, it is clear that in situations where English is not the language in which most people communicate in, there is also likely to be great exclusion in terms of development. Powel [17] shows how the increasing domination by English of the development sector both exclude those who are not fully fluent in English, and just as importantly '[disempowers] itself (English) by ensuring its ignorance of vitally (and in the case of China increasingly importance) important intellectual traditions. By failing to engage systematically with local languages, the development sector limits its understanding of and its ability to communicate with most of its intended beneficiaries. The paper argues that addressing the issue of language fully would have large financial and organizational implications, and failure to do so also carries the high costs of ignorance and inefficient communication. Powel [18] argues that "If development is 
to be about life, it has to be able to connect with the languages in which its beneficiaries live."

From the above, it is clear that for sustainable development to reach the intended people, it must engage them in their MT or local languages. This is mainly due to the reason that MTs or local languages are the languages through which people have learnt how to think and how to communicate and therefore they certainly can be harnessed to ensure that communities develop local solutions to the SDGs challenges.

\section{Local Languages/Mother Tongues and the SDGs: Why Mother Tongue (MT)?}

In this section we will discuss the importance of MT in life generally and especially to the SDGs. We shall consider MT as the first language that a baby learns or ones birth language. Before discussing the importance of MT, let's examine the Kenyan language situation. Kenya is a multilingual country. Most Kenyans speak up to three languages namely: first language (MT), Kiswahili and English. These languages play different roles in the lives of Kenyans. Kiswahili for instance is the national and official language. Despite Kiswahili being a national language, there are certain areas where Kiswahili is not used in Kenya. English on the other hand, is also an official language used mainly in formal or official circles. MTs or native languages spoken in Kenya account for most social use in family gatherings, in funerals in political rallies etc. However, majority of Kenyans especially those who live in the rural areas and even in urban areas easily understand and are reachable using their MT/local languages on all important issues. How can a country like Kenya with such a dynamic language situation therefore ensure that the SDGs reach the grassroots for sustainable development? IF for example the SDGs can are translated into Kiswahili the national language chances are they will not reach all Kenyans. The SDGs will be more meaningful if they are translated in a language each community understands their MT.

MT has a crucial role to play in our lives. On the social front for example, studies have shown that cognitive development as well as intellectual development is comparatively faster in those who are fluent in their mother tongue. When children develop skills in their mother tongue, they are simultaneously fostering a whole host of other essential skills, such as critical thinking and literacy skills. It is these skills that they take with them into formal education, and research tells us that any skills and concepts gained in the learner's home language don't have to be re-taught when they transfer to a second language. [19]. According to Cummins [20], children who come to school with a solid foundation in their mother tongue develop stronger literacy abilities in the school language. MT learning and development is part of the process in which the child also learns values, culture and the worldview. Acquisition of language goes hand in hand with the acquisition of a worldview.

Languages especially our MTs are also the most important way of keeping our culture alive. If one has a firm grasp of their Mt, it is easier for him or her to master a new language. MT being the language which a child starts hearing after being born, it assists in providing a definite shape to our emotions and thoughts. Also, knowing your MT well is a matter of pride. It boosts one's confidence and creates awareness in the individual's mind while also helping one connect with their cultural identity in a better manner. Similarly, there are also commercial benefits of MT. For instance as the international businesses go the local way, the importance of mother tongues has exponentially increased.

It is also important to note that communication is an important prerequisite of development and this is manifested through language. Language must be seen to be communicating the intended meaning as a vehicle to achieving set goals. The language that provides for people a definite shape to their emotions and thoughts (MT) is necessary to achieve this. The importance of MT manifests itself in both the social and economic facets of life. According to Nyasulu [20], "the role of language in socio-economic development cannot be overemphasized. Where there is no language there is no development, and this is a fact.... effective communication facilitates development. Thus for the SDGs effective implementation language and this case MT is important.

MT or local languages can also be viewed as the language that one learns at home mainly from parents. In some quarters, it is viewed as the language of one's ethnicity, sometimes disregarding one's proficiency in the same, Mweri [19]. These local languages play a crucial role in facilitating community participation in the socio-economic development of any nation. A study done on projects carried out in five communities from five Local Government areas by the Ebonyi State Community and Social Development Agency (EBCSDA), Nigeria, revealed that successful implementation of sustainable socio-economic development projects are better achieved through both the use of local languages and participation of the target population. The import is that any person involved in the process called development must understand that languages gauge can be of great assistance to people involved in the social process of enhancing the quality of people's life, Okafor and Noah [20].

According to Manyozo [21] the fact that any development would involve the coming together of stakeholders in some form of dialogue, then the language of the people holds the key to sustainable development. Surprisingly language issues have always been neglected in development discourse. For example, according to the Intrac blog, "the Sustainable Development Goals (SDGs) 
aim to put the most vulnerable populations first and to leave no one behind. This implies communicating in a multiplicity of languages, yet the SDGs are silent on language issues." [22].

The absence of any mention of language in the SDGs was the topic of a UN Symposium titled 'Language, the Sustainable Development Goals and Vulnerable Populations,' held in New York on 11-12 May 2017. This symposium is an indicator of the recognition of language in achieving the SDGs. The symposium though focused mainly on how vulnerable populations can be reached using language. The symposium however did not focus on a language based approach for the attainment of the SDGs as a whole which is what we are advocating for. It has been proven that, open and more accessible discussions in local languages create a collegial and congenial atmosphere for community participation. The idea of linguistic rights which this paper is advocating for fits in well with the current agenda in development where emphasis is on participatory empowerment and ownership of the process of development by the target community. It is a fact that one can only participate actively in a social change if one has the access and right (to a language), individually and collectively. Okafor and Noah, [23]. The adherence to these linguistic rights can mean success or failure of sustainable development goals set by the UN.

\subsection{The SDGs}

The Sustainable Development Goals (SDGs) are essentially an expansion of the Millennium Development Goals (MDGs). The SDGs were a reaction to the weakness of the MDGs. While initially we had only eight MDGs, the SDGs were expanded to seventeen [24]. In this section we shall examine each SDG and analyse the role of MT or local languages in their achievement.

Each of SDG has specific targets expected to be achieved by 2030. For example, the achievement of SDG 1 which focuses on ending poverty and all its forms everywhere, requires a concerted effort from governments and all stakeholders to improve incomes at the grassroots level where local languages are spoken. If information on how to improve incomes and eradicate poverty is communicated in local languages then meaningful development can take place. This means any information on hunger reduction is given in native languages or dialects of the immediate environment of the benefiting communities so as to enhance interaction with them. According to the UN, this interaction requires active engagement with policymakers to ensure that the rights of citizens are heard and promoted. Governments need to be encouraged to help create an enabling environment to create employment and job opportunities for the poor and the marginalized. Strategies by governments should stimulate pro-poor growth, and reduce poverty. [25]

The private sector is not to be left out. The private sector should create inclusive wealth thus contributing to poverty reduction. It can promote economic opportunities for the poor, focusing on segments of the economy where most of the poor are active, namely on micro and small enterprises and those operating in the informal sector. Not to be left behind are the science and academic community which can help by increasing the awareness about the impact of poverty. Science provides the foundation for new and sustainable approaches, solutions and technologies to tackle the challenges of reducing poverty and achieving sustainable development. The contribution of science to end poverty has been significant. For example, it has enabled access to safe drinking water, reduced deaths caused by water-borne diseases, and improved hygiene to reduce health risks related to unsafe drinking water and lack of sanitation [26]. Such contributions by science will have more impact if they are accessible to local communities through the languages they use.

The interaction between local people and policy makers, government and experts also requires high level of literacy in the local languages for both the development experts and the locals. If people can read and write their local languages then development literature in their language becomes easy to follow thus the need for adult literacy classes. As Bagwasi, in the SIL handbook puts it: "in order to reduce poverty the adult education program should be mediated in languages that enable the learners to be confident to participate in discussions and activities of their education and economy." He continues saying, Thus education that is culture - sensitive and appropriate helps the members of the community to manage the development process and activities and the resulting income thus enjoying an improved quality of life. SIL [27]. UNESCO, sums up this relationship between language and poverty eradication well below:

People's languages are vitally important to them. Through language, people communicate, share meaning and experience their sense of individual and community identity...Recognizing the profound importance that people place on their languages is a core insight for tackling poverty and hunger.

SDG 2 aims at ending hunger, achieving food security and improved nutrition and promoting sustainable agriculture. According to the UN, if done right, agriculture, forestry and fisheries can provide nutritious food for all and generate decent incomes, while supporting people-centered rural development and protecting the environment. This can be achieved through effort at home, at work and in the community for example by supporting local farmers or markets and making sustainable food choices, supporting good nutrition for all, and fighting food waste. Similarly, one can also use his/her power as a consumer and voter, demanding businesses and governments make the choices and changes that will make "Zero Hunger" a reality [28]. To ensure the success of this goal, there is need for a culture-sensitive approach that puts local languages or 
MTs in the forefront. Information on ending hunger, achieving food security and improving nutrition must be in the language of the targeted groups so that they can own any initiative to this end. [29]

Through SDG 3, the UN views ensuring healthy lives and promoting the well-being for all at all ages as essential to sustainable development. WHO in 1948 defined health as a "State of complete physical, mental, and social wellbeing, and not merely the absence of disease or infirmity." This definition however, is not devoid of controversies. Some scholars thinking that it is no longer tenable especially in the absoluteness of the word "complete." Some scholars like Huber et al [30] have therefore proposed a shift on the emphasis towards the ability to adapt and self-manage in the face of social, physical, and emotional challenges. Other definitions of health include one that sees health as that balanced condition of the living organism in which the integral, harmonious performance of the vital functions tends to the preservation of the organism and the normal development of the individual. According to the Business Dictionary.com, "Health is a dynamic condition resulting from a body's constant adjustment and adaptation in response to stresses and changes in the environment for maintaining an inner equilibrium called homeostasis."

Some of the targets for this SDG aim at reducing the global maternal mortality ratio, ending preventable deaths of newborns and children under 5 years of age end the epidemics of AIDS, tuberculosis, malaria and neglected tropical diseases among other goals [31]. This definitely calls for health education. Health education can be rendered ineffective if any language barriers exist.

These language barriers need to be surmounted to be able to achieve the goals of this SDG. When questions of disease prevention and treatment are transmitted through local languages or MT, there is a higher likelihood of this information reaching those intended. One often used saying is that "if you want to educate the whole community educate a mother.” If most mothers are literate in their MT, they will most probably be well placed to take care of themselves and the entire family. They could assist in the fight against diseases within their communities as long as they have the capacity to get important health information in a language they understand. On the other hand, health information that is misunderstood due to language barriers can be dangerous. Thus there is need for adult literacy on health education in MT targeting local communities so as to achieve this goal.

According to SIL, A mother is better able to care for herself and her family when she is literate in her mother tongue and has access to health information in a language she understands well. Language development facilitates the introduction of new concepts and the accurate translation of new terminology in MT is important. SIL gives the example of Alimata to concretize this argument: Alimata, a rural woman in the Muyang community from the Far North Province (in Cameroon), has decided to help women of her area. She attended the two-year literacy program in the Muyang language and learned to read and write in her mother tongue. Because of her literacy skills, Alimata was then able to receive training from a local health service. Now she assists nurses and also plays the role of mid-wife in her village.

SDG 4 deals with quality education. According to the $\mathrm{UN}$, obtaining a quality education is the foundation to improving people's lives and sustainable development. However, in most developing countries, many children enter the classroom unable to understand the language they are taught in [32]. Many countries still use the colonial languages, or a dominant national or international language, which young children do not speak at home. According to UNESCO, "Africa is the only continent where the majority of children start school using a foreign language." Education is almost universally offered in the old colonial languages - French, English or Portuguese - which most young people do not speak at home.

The use of foreign languages in education is as a result of what Cummins [33] calls the "Assimilationist Policies" in education which discourage students from using their MT. "Assimilationist policies" are based on the belief that usage of MT is not only detrimental to national integration, but that it is also an inadequate tool for teaching educational concepts and knowledge. In 1953 however, UNESCO debunked this myth by underscoring the importance of educating children in their MT. UNESCO, 2004 underlined the fact that worldwide the choice of the language of instruction and language policy in schools is critical for effective learning. According to Cummins [34], a child who begins his/her education in mother tongue gains numeracy and literacy skills faster than one who's early and formative education is done in a foreign language. Using the skills learnt from MT, children can learn other languages for the purpose of wider communication. This is because MT learning and development and use is part of the process in which the child also learns values, culture and the worldview. Acquisition of language goes hand in hand with the acquisition of a worldview. Cummins [35]. In terms of literacy skills, children are better placed to become literate if they learn from the first instance in their MT. This then gives them a chance to move gradually to another language. This is what Hornby [36] refers to as "additive bilingualism" which gives positive values to both the first language (MT) and the second language. This approach, therefore, builds on the first language for purposes of learning a second language. SDG 4 therefore would require that basic education is conducted in MT.

SDG 5 is about gender equality. The UN views gender equality as not only a fundamental human right, but also a necessary foundation for a peaceful, prosperous and sustainable world. Providing women and girls with equal access to education, health care, decent work, and representation in political and economic decision-making 
processes will fuel sustainable economies and benefit societies and humanity at large. [37]

Discrimination is a multifaceted phenomenon, and it is about social exclusion as a process. Social exclusion occurs where particular groups are excluded by mainstream society from fully participating in economic, social and political life. Discrimination can exist explicitly, through institutions, norms and values. It can also have invisible impacts, where values and ideas affect the self-perceptions of excluded people, and their ability to claim their rights. It is also about the misuse of equality, and about the unequal treatment that leads toward further inequality. Gorman, [38]

Girls and women are among the most vulnerable groups and they normally suffer structural discrimination. Structural discrimination is defined as a situation experienced when certain communities and societies have discriminatory views about certain people and other societies. They tend to pass on the discriminatory views down through their generations. Human Rights Commission [39]. They have certain sets of beliefs that they follow and have pre-conceived ideas that are mostly highly rigid and retrogressive. Majority of the world's illiterate population are women. According to UNESCO [40] of the world's 774 million illiterate adults, $2 / 3$ are women. The share of illiterate women has not changed for the past 20 years. Among the world's 123 million illiterate youth, 76 million are female. These gender disparities remain persistent, with little change over time. Cultural practices, prejudices and stereotypes are used to put the woman in her place. To empower woman especially in rural areas, MT literacy can open avenues that can lead to the achievement of this SDG. Once the woman is educated all the other SDGs will be easy to achieve. UNESCO (ibid) asserts that: Study after study demonstrates the positive impact of gender equality in education. For example, it gives the following facts:

i) Educated mothers mean healthy children. A child born to a mother who can read is $50 \%$ more likely to survive past the age of 5 .

ii) Each extra year of a mother's schooling reduces the probability of infant mortality by $5 \%-10 \%$.

iii) An educated female population increases a country's productivity and fuels economic growth. Some countries lose more than $\$ 1$ billion a year by failing to educate girls to the same level as boys.

Gender equality can be achieved effectively through MT literacy. According to Benson, "The learner's mother tongue holds the key to making it more inclusive for all disadvantaged groups, especially for girls and women." [41]

Clean, accessible water for all is an essential part of the world we want to live in, this is the matter of interest for SDG 6. There is sufficient fresh water on the planet to achieve this. But due to bad economics or poor infrastructure, every year millions of people, most of them children, die from diseases associated with inadequate water supply, sanitation and hygiene [42].The achievement of this SDG can be done through keeping governments accountable by the civil society, investments in water research and development, and promotion of the inclusion of women, youth and indigenous communities in water resources governance [43]. Generating awareness of these roles and turning them into action will lead to win-win results and increased sustainability and integrity for both human and ecological systems.

Development of community water supplies and sanitation results in improved social and economic conditions and improved health, Davis et al. [44]. Okun [45] also recognizes the importance of clean, accessible water for as he puts it, "the benefits of improved water supply and sanitation are many, including prevention of disease, improved basic health care, better nutrition, increased access to institutions such as health centers and schools, improved water quality, increased quantity of and access to water, reduction in time and effort required for water collection, promotion of economic activity, strengthening of community organization, improvements in housing, and ultimately, improved quality of life." It is important to note that community development project initiation requires knowledge of the people, their culture, their country, and their language to be able for example to get a clear understanding of the local context within which water and sanitation projects can function well. WHO, [46].

In most societies, women have primary responsibility for management of household water supply, sanitation and health. Water is necessary not only for drinking, but also for food production and preparation, care of domestic animals, personal hygiene, care of the sick, cleaning, washing and waste disposal (GWTF -2005-2015). This calls for women's greater participation and involvement in water-related development effort and the need to give them a central role. This role can be played well if women are literate in their MT or local languages so that they can understand and come up with local solutions to water and sanitation issues. Knowledge of the local language here is of utmost importance since through it, people are reached easily leading to improved health and other benefits. Brayan and Varant [47].

The SDG 7 aims at ensuring access to affordable, reliable, sustainable and modern energy for all. This SDG is important to the whole Sustainable Development agenda, as sustainable energy is needed in the implementation of almost all the other goals in the agenda, from eradicating poverty to fighting climate change. The Accelerating SDG 7 achievement: Policy briefs in support of the first SDG 7 review at the UN High-Level Political Forum 2018, supports this assertion when it says: "Without urgent action, the world will fall short of its 2030 energy targets and, consequently, fail to achieve the Sustainable Development Goals (SDGs)" 
The energy saving jiko's (stove) of Kenya which provide rural communities with energy efficient cooking stoves thus reducing the demand for fire wood as a source of energy drastically is a good example of how to achieve this. [48] Action towards affordable, reliable and modern energy should also start with mobilization of local communities to understand their energy needs well this is best done through their MT.

SDG 8 deals with decent work and economic growth. According to ILO Director-General, Guy Ryder, the "Rethinking Work for Human Development" (2015) UNDP report, pressing global challenges require that growth must be accompanied by policies and actions that also tackle unemployment, underemployment, inequality and the denial of voice and rights." The UNDP report places decent work at the heart of sustainable development. [49]

Providing youth with skills that match labour market demands, giving them access to social protection and basic services regardless of their contract type, as well as levelling the playing field so that all aspiring youth can attain productive employment regardless of their gender, income level or socio-economic background [50]. Governments can work to build dynamic, sustainable, innovative and people-centered economies, promoting youth employment and women's economic empowerment, in particular, and decent work for all. Local authorities and communities can renew and plan their cities and human settlements so as to foster community cohesion and personal security and to stimulate innovation and employment.

However, if economic growth doesn't mean anything it leaves people out. Sustainable economic growth must speak the language of the people for it to have meaning. Thus local languages must therefore be used to create jobs and achieve full productive employment and decent work for all women and men including persons with disabilities. As Okombo [51] aptly puts it in terms of the economic benefits of MT,

There are also economic benefits to the country/county, including: promoting development projects (in agriculture, ealth, education, etc), and promoting trade and commerce within a county. We may also mention benefits based on social mobilization and behaviour change communication, including: HIV/AIDS campaigns, anti-FGM campaigns, vaccination campaigns, voter-registration campaigns, population census campaigns, and anti-drug abuse campaigns, not to mention campaigns for registration of births and deaths, among many others. (Pg 12)

In other words, there is no true development without language development. (SIL 2016). It further states that Literacy is a core component of the right to education and an indispensable prerequisite to lifelong learning ....The initial language of instruction should match the language of the home and community. Similarly, we feel that the initial language for promotion of sustained, inclusive and sustainable economic growth must match the language of the home and the community so that productive employment and decent work for all can be realized.

SDG 9 addresses industry, innovation and infrastructure. According to the UN, Investments in infrastructure transport, irrigation, energy and information and communication technology - are crucial to achieving sustainable development and empowering communities in many countries [52]. It has long been recognized that growth in productivity and incomes, and improvements in health and education outcomes require investment in infrastructure. Sustained investment in infrastructure and innovation are crucial drivers of economic growth and development. With over half the world population now living in cities, mass transport and renewable energy are becoming ever more important, as are the growth of new industries and information and communication technologies [53]. Infrastructure makes life better, economies more competitive, and while being built, offers jobs to the value chain. On the other side, however, infrastructure also massively consumes cement and increases emissions. It is one of the most gender-inequal labour markets too.

For infrastructural development or any other form of development to be sustainable it must involve the people it is meant for in terms of consultation and also in terms of job creation. Locals must be involved so that they can understand and own such projects. The MT or local languages is necessary to achieve this.

SDG 10 handles reducing inequality. Policies should be universal in principle, paying attention to the needs of disadvantaged and marginalized populations. However, the 85 richest people in the world own as much as the poorest half of humanity. Income inequality is on the rise, in developed and developing countries alike [54]. According to the Organization for Economic Co-operation and Development (OECD), income inequality is at its highest level for the past half century. The average income of the richest $10 \%$ of the population is about nine times that of the poorest $10 \%$ across the OECD, up from seven times 25 years ago. These widening disparities are a call for action that requires the adoption of sound policies to empower the bottom percentile of income earners and promote economic inclusion of all regardless of sex, race or ethnicity.

According to Human Rights Watch [55], emphasis should put on the importance of development reaching the most marginalized populations, including indigenous peoples. It can go some way towards achieving this by including: a specific target of addressing the social and economic needs of the most marginalized or discriminated against groups in each country. This framework should establish the methodology for identifying marginalized or disadvantaged groups, but the groups identified should vary from country to country. Reaching such groups in a 
language they understand is paramount so that they are able to understand their rights as right holders. This however calls for having language policies that have planned a prominent role in nation-building and promotion of inclusive development

SDG 11 aims at ensuring access to adequate, safe and affordable housing and basic services for all as well as the upgrading of slums. It also aims at provision of access to safe, affordable, accessible and sustainable transport systems, improving road safety, notably by expanding public transport, with special attention to the needs of those in vulnerable situations, including women, and children, persons with disabilities and older persons among other targets [56]. However, many common urban challenges including congestion, lack of funds to provide basic services, a shortage of adequate housing and declining infrastructure still exist.

The achievement of cities of opportunities for all, with access to basic services such as energy, housing, transportation etc. is reliant on a culture-sensitive approach and language as the sociocultural base for sustainable development. As Kwesi Kwaa Prah [57] puts it, “African development projects and efforts have the greatest chance of success if innovative ideas and their communication are couched in indigenous languages, which reach the rural masses more immediately and more directly.” Kaplan [58], also asserts that, "all successful developing countries have depended on their own language and sociocultural base for development, any meaningful human settlement to be inclusive, safe, resilient and sustainable, and each country must tailor their language policies to achieve this."

SDG 12 covers responsible consumption and production. The UN views sustainable consumption and production as being about promoting resource and energy efficiency, sustainable infrastructure, and providing access to basic services, green and decent jobs and a better quality of life for all. Its implementation helps to achieve overall development plans, reduce future economic, environmental and social costs, strengthen economic competitiveness and reduce poverty [59]. Definitely the unsustainable pattern of consumption and production has been widely recognized as the major cause of the deterioration of the environment and that it also exacerbates poverty and social inequity. To achieve this goal, there is need to take into consideration local needs and priorities which calls for respect for peoples cultures and their local languages which can be used to enhance the meeting of this goal by developing local solutions.

SDG 13 talks of climate change which is now affecting every country on every continent. It is disrupting national economies and affecting lives, costing people, communities and countries dearly today and even more tomorrow. According to Terralingua, "Language, knowledge and the environment have been intimately related throughout human history. This relationship is still apparent, especially in indigenous, minority and local societies that maintain close material and spiritual ties with their environments. Over generations, these peoples have accumulated a wealth of wisdom about their environments and its functions, management and sustainable use." (As cited in SIL) [60]. Sustainable environmental management requires acknowledge and use of the link that exists between language and knowledge so as to be able to harness local knowledge in combating climate change.

SDG 14 is about life below water. The Sustainable Development Goals (SDGs) create a framework to sustainably manage and protect marine and coastal ecosystems from land-based pollution, as well as address the impacts of ocean acidification. Enhancing conservation and the sustainable use of ocean-based resources through international law will also help mitigate some of the challenges facing our oceans [61]. The world's oceans their temperature, chemistry, currents and life - drive global systems that make the Earth habitable for humankind. Thus the need to ensure protection of vulnerable habitats through increased international cooperation. Locally ocean-friendly choices are required when buying products or eating food derived from oceans and consuming only what we need. Most importantly, we can spread the message about how important marine life is and why we need to protect it [62]. These messages though need to be packaged in languages that reach the masses so that through their local languages more people can be reached.

SDG 15 deals with life on land. Inevitably, we change the ecosystems we are a part of through our presence, but we can make choices that either affirm, diversity or devalue it. Some things we can do to help include recycling, eating a locally-based diet that is sustainably sourced, consuming only what we need, and limiting energy usage through efficient heating and cooling systems [63]. We must also be respectful toward wildlife and only take part in ecotourism opportunities that are responsibly and ethically run in order to prevent wildlife disturbance. Well-managed protected areas support healthy ecosystems, which in turn keep people healthy.

According to SIL Environmental preservation principles are communicated between languages through language-based development programs and literature production. Deforestation is a critical problem worldwide. As local populations learn appropriate technology while drawing on traditional knowledge of flora and fauna, they meet economic needs while protecting the environment. It is therefore critical to secure the involvement of the local communities in the development and management of these protected areas.

The general goal of this SDG is to sustainably manage forests, combat desertification, halt and reverse land degradation, and halt biodiversity loss. Deforestation and desertification - caused by human activities and climate change - pose major challenges to sustainable development and have affected the lives and livelihoods of 
millions of people in the fight against poverty [64] Efforts are being made to manage forests and combat desertification. This can be effectively achieved by involving locals by making information on the relationship between human activities and climate change available in a language they understand - their MT so that they can seek local solutions.

Goal 16 of the SDGs is dedicated to the promotion of peaceful and inclusive societies for sustainable development, the provision of access to justice for all, and building effective, accountable institutions at all levels. Inclusivity in this case is the process of increasing participation of society and reducing their exclusion from all institutions. It means that citizens must take a genuine interest in what their government is doing, and raise awareness in their communities about the realities of conflict and the importance of peaceful and just societies [65]. It involves taking action in your communities through the help of schools, clubs, teams and organizations to promote peace and justice. The importance of peaceful coexistence is a reality that can be communicated effectively through languages that are understood by each society - local languages.

Partnership for the goals is the concern of SDG 17. A successful sustainable development agenda requires partnerships between governments, the private sector and civil society. These inclusive partnerships built upon principles and values, a shared vision, and shared goals that place people and the planet at the center, are needed at the global, regional, national and local level. Local communities must mobilize action on the implementation of the SDGs [66]. Similarly, governments would need to get into partnerships with businesses for the successful implementation of the SDGs. Governments can mobilize to reach their people through local languages for a clear understanding of the SDGs and their implementation otherwise nothing much may be achieved come 2030 .

\section{Conclusions}

The SDGs, which represents a new universal set of goals, targets and indicators that UN member states will be expected to use to frame their agendas and political policies over the next 15 years (2015-2030) are a noble idea. However, as to whether in the next fifteen years these goals and their targets will be reached is debatable. This is because most of the strategies for their implementation hardly ever take cognizance of the crucial role of language. Language is one of the most neglected areas in the field of development. Despite its being neglected, it is one of the most crucial ingredients in sustainable development. As Nelson Mandela once put it: "If you talk to a man in a language he understands, that goes to his head. If you talk to him in his language that goes to his heart," Laka [67]. To get to the hearts and souls of those targeted by these SDGs then Mother tongue or local languages have to play a critical role.

Kaplan [68] also sums up the crucial role of MTs or local languages. He says:

Instead of forcing whole populations to learn foreign languages, much greater effort should be made to translate world knowledge into major indigenous tongues such as Arabic, Hausa, and Punjabi... Certainly, no society that has successfully developed has depended as heavily on foreign resources, foreign political models, foreign languages and foreign laws as fragile states typically do today. All successful developing countries have depended on their own Language and sociocultural base for development, importing Western ideas and technology as needed, and integrating these with local institutions in a hybrid manner.

Since MT or local languages are the languages through which people have learnt how to think and how to communicate, it is important to note that MTs can be harnessed through consorted effort by government or state and non-state players to ensure that communities develop local solutions to the SDGs challenges. Overdependence on foreign language to drive the SGDs agenda does not auger well for their success because as Bodomo [68] asserts: “...every language is an efficient tool for encoding the peculiarities of the particular environment in which a people live. Thus ...languages relate first and foremost to particular cultures, each individual language seems to represent the speakers of the culture it encodes." This therefore means, that to reach people, there is need to target the tool they use for encoding their particularities and this tool is their MT. To Bodomo, MT is that language seen as a granary, a repository of the world-view of its speakers, it is this particular language that best contains and expresses the indigenous belief systems - socio-cultural, political, economic and technological - of any society. New belief systems are immediately related to these existing systems. It is in this sense that we notice that the most intelligible and intelligent reactions by speakers to new ideas and technologies are registered through their language.

Therefore, if we view sustainable development as development that meets the needs of the present without compromising the ability of future generations to meet their own needs, then we shall recognize that it can only be achieved through the involvement of those targeted by this development. Similarly, if development is seen as the sustainable socio-cultural, economic and technological transformation of a society, then language becomes an important variable in this development process; the indigenous language of the society in focus becomes causally related to its development efforts. Therefore the indigenous languages must be placed right at the center of any development discourse. Bodomo [69].

In conclusion, if development involves the appropriate transformation of the socio-cultural, political and economic systems of a society, and if language is seen as a repository and a tool for the expression and communication 
of these very socio-cultural, political and economic belief systems of the society, then it goes without saying that a successful conceptualization and implementation of this societal transformation can only be achieved through the use of the MT or the languages indigenous to societies. Bodomo [70].

\section{REFERENCES}

[1] The global Taskforce of local and regional government (2016). Roadmap for Localizing the SDGs: Implementation and Monitoring at Subnational Level. Available online at https://sustainabledevelopment.un.org>content>ocuments>C ommitments

[2] The UN General Assembly (1987). Report of the world Commission on Environment and development: Our common future.

[3] Bonvillain, N. (2003). Language, Culture, and Communication: The Meaning of Messages (4th edn. ed.). Upper Saddle River, N.J.: Prentice Hall.

[4] UNDP. Sustainable Development Goals. Available online at https://www.undp.org > corporate > brochure > SDGs_Bo oklet_Web_En

[5] UNESCO. Global citizenship education. Available online at (https://en.unesco.org > themes > gced > languages)

[6] Bruthiaux, P. 2000. Supping with the dismal scientists: Practical interdisciplinary in language education and development economics. Journal of Multilingual and Multicultural Development 21(4), 269-291

[7] Markee, Numa. (2002). Language in development. Spec. iss. of TESOL Quarterly 36.3

[8] Mikulas Huba, The Society for Sustainable Living in the Slovak Republic. Coleman, H (2011) Developing Countries and the English language: Rhetoric, risks, roles and recommendation. British Council /Design Department/Z41310 Spring Gardens London SW1A 2BNUK. www.britishcouncil.or

[9] Erling, E. J., Seargeant, P. and Solly, M. (2014) English in rural Bangladesh: How is language education perceived as a resource for development in rural communities? English Today. 30: 4, pp. 15-21.

[10] Bourdieu, P (1991) Language and Symbolic Power, trans. Gino Raymond and Matthew Adamson, Cambridge: Polity Press.

[11] Okombo, O. (2016). Approaching Mother Tongue Education as a Personal and Societal Development Strategy. The University of Nairobi Journal of Language and Linguistics, Vol. 5, 85-100.

[12] Erling, E. J., Seargeant , P. and Solly, M. (2014) English in rural Bangladesh: How is language education perceived as a resource for development in rural communities? English Today. 30: 4, pp. 15-21.

[13] diImam, S.R. (2005). English as a global language and the question of nation-building education in Bangladesh. Comparative Education41 (4), 471-486.

[14] Benson, C. 2004. The importance of mother tongue-based schooling for educational quality. Background paper prepared for the 'Education for All' Global Monitoring Report 2005, The Quality Imperative, UNESCO. Available online at http://unesdoc.unesco.org/images/0014/001466/1 46632e.pdf

[15] Trudell (2009). Local-language literacy and sustainable development in Africa. International journal of educational development Volume 29 Issue 1Pages 73-79: Pergamon

[16] Hanushek E.A. and Woessmann L. (2008).The Role of Cognitive Skills in Economic Development. Journal of Economic Literature 2008, 46:3, 607- 668

[17] Powell, M (2006). "Which knowledge? Whose reality? An overview of knowledge used in the development sector." In Development practice 16 (2), 518-532.

[18] Powell, M (2006). "Which knowledge? Whose reality? An overview of knowledge used in the development sector.” In Development practice 16 (2), 518-532.

[19] Mweri, G.J. (2014. Diversity in education: Kenyan sign language as a medium of instruction in schools for the deaf in Kenya. Multilingual Education 2014, 4:14 Springer Publishers. Available online at https://link.springer.com/ar ticle/10.1186/s13616-014-0014-1

[20] Okafor, M and Noah, P. (2014). The role of local languages in Sustainable community development projects in Ebonyi state, Nigeria. European Scientific Journal December 2014 edition vol.10, No.35 ISSN: 1857 - 7881 (Print) e - ISSN 1857- 7431.

[21] Manyozo, L. (2006). Manifesto for development communication: Nora Quebral and the Los Baños School of Development Communication.Asian Journal of Communication, 16 (1): 79-99

[22] Intrac (2017. Why are Languages Missing from the Sustainable Development Goals? Available online at https://research.reading.ac.uk > research-blog > why-are-la nguages-missing

[23] Okafor, M and Noah, P. (2014). The role of local languages in Sustainable community development projects in Ebonyi state, Nigeria. European Scientific Journal December 2014 edition vol.10, No.35 ISSN: 1857 - 7881 (Print) e - ISSN 1857- 7431.

[24] UNDP. Sustainable Development Goals. Available online at $h t t p s: / / w w w . u n d p . o r g ~>$ corporate > brochure > SDGs_Bo oklet_Web_En

[25] UN-DESA (2012). Promoting empowerment of people in achieving poverty eradication, social integration and full Employment integration and full employment and decent work for all. Available online at (https://www.un.org > esa > socdev > publications > FullSurveyEmpowerment)

[26] Fourie, F (2018).Creating jobs, reducing poverty I: Why the informal sector should be taken seriously and enabled properly. Available online at (www.econ3x3.org > article > creating-jobs-reducing-poverty-i-why-infor).

[27] SDGs: Goal 2: Zero hunger. Available online at (https://www.un.org > sustainabledevelopment > hunger). 
[28] SIL (2016) Language and the Sustainable Development Goals: A Symposium. United Nations complex in New York on 21-22 April.

[29] SDGs: Goal 2: Zero hunger. Available online at (https://www.un.org > sustainabledevelopment > hunger).

[30] Huber, M et al (2011). How shall we define health? doi: http://dx.doi.org/10.1136/bmj.d4163. BMJ 2011; 343:d416 3

[31] UNDP- Global goal MUN. Goal 3: good health and wellbeing. Available online at https://globalgoalsmun.org > goal-3-good-health-and-well-being

[32] UNICEF. Education. Available online athttps://www.unice f.org > education

[33] Cummins, J. 2003. Bilingual children's mother tongue: Why it is important for education. Toronto: University of Toronto Press.

[34] Cummins, J. 2003. Bilingual children's mother tongue: Why it is important for education. Toronto: University of Toronto Press.

[35] Cummins, J. 2003. Bilingual children's mother tongue: Why it is important for education. Toronto: University of Toronto Press.

[36] Hornby, PA. (1977). Bilingualism, psychological, social, and education implications. New York: Academic Press.

[37] UN. SDGs: Goal 5: achieve gender equality and empower all women and girls. Available online at https://www.un.org > sustainabledevelopment > gender-equ ality

[38] Gorman, L. (2008). Discrimination: Concise Encyclopedia of Economics (2nd ed). Indianapolis: Library of Economics and Liberty.

[39] Human Rights Commission HRC. (2011). Structural discrimination: The need for systemic change to achieve racial equality. A Discussion Document Presented.

[40] Benson, C (2005). Girls, education equality and mother tongue, UNESCO-Bangkok

[41] UNESCO (2014). International Women's Day. Equality for Women is Progress for All.www.unesco.org, new , international-days > international-womens-day-2014.

[42] SDGs: Goal 6: Ensure access to water and sanitation for all. Available online at https://www.un.org > sustainabledevelo pment > water-and-sanitation

[43] UNO-IDfA. A 10 Year Story: The water for life decade 2005-2015 and beyond. Available online at https://www.un.org > waterforlifedecade > pdf > WaterforLif eENG

[44] Davis, J., Garvey, G., and Wood, M. (1993). Developing and Managing Community Water Supplies. (Oxfam Development Guidelines No. 8). Oxford: Oxfam.

[45] Okun, Daniel A. (1988). "The Value of Water Supply and Sanitation in Development: An Assessment.” In: American Journal of Public Health, vol. 78, no. 11, pp. 1463-1467

[46] WHO (2019). Drinking Water: Key facts. Available online at (https://www.who.int > Newsroom > Fact sheets > Detail)
[47] Brayan,E \& Varant, J. (2008). Strategies for Promoting Gender Equity in developing countries: Lessons, challenges and opportunities. Woodrow Wilson International Center for scholars. Available online at https://www.wilsoncenter. org > sites > default > files > GenderEquity

[48] SNV- Netherlands Development Organization. (2018) Story of Change: Kenya's clean cooking champions. Smart Development Works. Available online at www.snv.org , update > story-change-kenyas-clean-cooking-champions

[49] ILO. International Labour Conference: decent work for sustainable Development. Available online at https://www. ilo.org > english > standards , relm > ilc > ilc96 > pdf , rep-i-a).

[50] International labour conference (2005). Youth; Pathway to descent work report VI - Promoting youth employment tackling the challenge. Available online at Available online at (https://www.ilo.org > youthmakingithappen > PDF , rep-vi_en).

[51] Okombo, O. (2016). Approaching Mother Tongue Education as a Personal and Societal Development Strategy. The University of Nairobi Journal of Language and Linguistics, Vol. 5, 85-100.

[52] SDGs: Goal 9: Build resilient infrastructure, promote sustainable industrialization and foster innovation. Available online at (https://www.un.org > sustainabledevel opment > infrastructure-industrializat).

[53] Shapiro (2019). Are affordable homes the answer to empowering the SDGs? Available online athttps://www.un dp.org > Home > Sustainable Development Goals)

[54] SDGs: Goal 10: Reduce inequality within and among countries. Available online at https://www.un.org, sustainabledevelopment > inequality

[55] Human Rights Watch (2013). World Report 2013. Events of 2012

[56] SDG Tracker. Make cities inclusive, safe, resilient and sustainable. Available online at https://sdg-tracker.org > cities

[57] Okafor, M and Noah, P. (2014). The role of local languages in Sustainable community development projects in Ebonyi state, Nigeria. European Scientific Journal December 2014 edition vol.10, No.35 ISSN: 1857 - 7881 (Print) e - ISSN 1857- 7431.

[58] Kaplan, S (2012). Are Language Policies Increasing Poverty and Inequality?

[59] SDGs: Goal 12: Ensure sustainable consumption and production patterns. Available online at $h t t p s: / / w w w . u n . o r$ $g$ > sustainabledevelopment > sustainable-consumption-p

[60] UN. (2008). Achieving sustainable Development and promoting development cooperation. New York Available online at https://www.un.org , ecosoc > docs > pdfs , fina_08-45773)

[61] SDGs: Goal 14: Conserve and sustainably use the oceans, seas and marine resources. Available online at https://www.un.org > sustainabledevelopment > oceans).

[62] SDGs: Goal 14: Life below Water: why it matters.

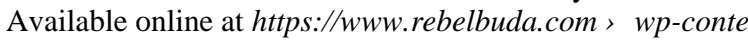


nt > uploads > 2018/11 > Goal-14)

[63] SDGs: Goal 15: GOAL 15: Life on land. Available online at www.unenvironment.org > why-do-sustainable-developmen t-goals-matter

[64] SDGs. GOAL 15: Life on land - Sustainably manage forests, combat desertification, halt and reverse land degradation, halt biodiversity loss. Available online at https://www.un.o rg > sustainabledevelopment > biodiversity

[65] SDGs. Sustainable Development Goal 16 Promote peaceful and inclusive societies for sustainable development, provide. Available online at https://sustainabledevelopmen t.un.org > sdg16

[66] Goal 17: Revitalize the global partnership for sustainable development. Available online at https://www.un.org > sustainabledevelopment > globalpartnerships

[67] Laka, I. (2014). Mandela was Right: The foreign Language test. available online at https://mappingignorance.org , 2014/02/03 > mandela-was-right-the-forei...

[68] Kaplan,S (2010. Fixing Fragile States: A New Paradigm for Development. Westport, CT London: Praeger Security International,

[69] Bodomo, A.B. (1996). On Language and Development in Africa: The Case of Ghana .Nordic Journal of African Studies 5(2): 31-51.Norwegian University of Science and Technology, Norway

[70] Bodomo, A.B. (1996). On Language and Development in Africa: The Case of Ghana .Nordic Journal of African Studies 5(2): 31-51.Norwegian University of Science and Technology, Norway

[71] Bodomo, A.B. (1996). On Language and Development in Africa: The Case of Ghana .Nordic Journal of African Studies 5(2): 31-51.Norwegian University of Science and Technology, Norway 